\title{
Translation Strategies of Metaphorical Idioms in Political Discourse
}

\author{
Hua $\mathrm{LI}^{1, \mathrm{a}}$, Yi BIAN², * \\ ${ }^{1}$ Beijing Wuzi University, No. 1 Fuhe Street, Tongzhou District, Beijing, China \\ Email: ${ }^{a}$ lihua@bwu.edu.cn
}

Keywords: Chinese idioms, Vehicle, Culture image, Translation strategy.

\begin{abstract}
Chinese idioms include set phrases, proverbs, colloquial and two-part allegorical saying which derived from fixed phrases and short sentences in long-term use. The remarks and speeches of Chinese new term of leadership tend to use more common and understandable colloquial language close to daily life. By borrowing household image, the metaphor not only manifests the unique Chinese cultural connotation but enhances language expressiveness. Therefore how to translate well the two main components of metaphorical Chinese idioms into English—vehicle and culture image and transmit exact meaning of in-depth culture becomes important in political discourse. In order to deal with such translation problem, neither literal nor liberal translation should be directly used. The paper discusses how to mix translation strategies on demand by different examples from current political remarks and speeches.
\end{abstract}

\section{Introduction}

In many Chinese current political discourse numerous idioms are used to reflect Chinese politics and economics and social culture and life. Under such multicultural Chinese background, how to translate the quoted metaphorical idioms in political speeches precisely becomes a new challenge. It is found that an idiom of similar meaning and form in target language may not always have an ideal expression. Therefore, it's a new target for translator to translate in maximum close to the feature and structure of source language and aptly to make readers understand with context.

Through illustration on the characteristic of metaphorical Chinese idioms and translation strategies of Chinese idioms within current political context, the paper explores how to flexibly process the cultural elements in metaphorical Chinese idioms in certain context by means of different translation methods so that the cultural characteristics can be truly translated in prominence. Many scholars have realized that many ways can be used in Chinese idiom translation but few of them systematically explain the concrete approaches to choose the word, sentence pattern, expression and appropriate translation strategy with relative style, register and rhetorical effect. Some scholars prefer the view of comparing different translation methods rather than employ each approach on different occasions.

\section{Literature Review}

So far much research has been conducted in relation to translation rules of Chinese idioms, rhetorical devices of idioms and the comparison between different translation theories. Zhang Guizhen (2000) stated the metaphors' function in idioms and summarized its translation approaches. she suggested that some means such as equivalent translation, analogical translation, imitative translation, and descriptive translation may be employed. The main objective is to convey the essence of the original without failing to represent its style and flavor. Form and content should be integrated. Yang Weihong (2009) pointed out that Chinese idioms have double meanings: image meaning and connotation meaning. He suggested that two basic principles in the process of translation should be followed. One is to choose connotation meaning in the difficult choice of image meaning and connotation meaning. The other is to preserve both image meaning and connotation meaning as condition permits. Xu Dongxia (2008) focused on the translation principle of idioms. Firstly, he researched on the similarities and discrepancies between English and Chinese idioms. Secondly, he analyzed the causes of the discrepancies between English and Chinese idioms. He also discussed 
several approaches to translate the idioms in terms of the translation theory of functional equivalent. Cao Pei (2013) mainly analyzed two methods domestication and foreignization. The two terms were created by American translation theorist Lawrence Venuti in 1995. She pointed out that the domestication is the ways and habits to make the translation in accordance with the target language readers. But to a great extent, domestication may easily leads to the loss of cultural connotation of many idioms in English, so that the reader does not have the opportunity to understand the profound China culture. In contrast, Foreignization method makes the translation go off the beaten track of the target language intentionally, and retains the original linguistic characteristics and traditional values generally. Thus domestication method is similar to liberal translation and Foreignization similar to literal translation. But both of them have their advantages and disadvantages, hence we should combine them together to express our idea more clearly. Over the past several years, both foreign scholars and Chinese scholars have conducted much research by comparison of idioms translation strategies between China and western countries. All researchers have reached the consensus that we should choose appropriate translation strategies when translating metaphorical idioms from Chinese to English.

\section{How to Translate Metaphorical Idioms}

It is by no means possible to find a one-size-fits-all technique for Chinese idioms translation. However, as on one can deny the fact that a proficient mastery of written translation strategies is the premise of a good delivery of the interpreting version. English learners should always familiarize themselves with these fundamentals so that they can use these strategies in a flexible manner during the interpreting process.

\section{Literal Translation and Liberal Translation}

Literal translation means to translate according to the literal meaning of an idiom, which can preserve the linguistic form and cultural image of Chinese idioms in the target language to a great extent. The strategy of literal translation will not only save time for the translator, but also keep the original feature of the source language. However, this method can only be used at the simple and lucid idiom, for those with reference to allusion, poetry, customs, annotation or some necessary words should be either added or omitted to assist understanding.

Liberal translation means to abandon structural features and alter the sense slightlyin order to achieve functional equivalence. American linguist and translator Eugene A. Nida has published a book named Translation and Translating, and put forward a concept of "dynamic equivalence (functional equivalence)". Liberal translation could also follow the "principle of equivalence" and interchange parts, finding equivalence not identity.

According to Nida's classification, "relatives (preposition and conjunctions)" are general corresponding relative words which can be omitted; find the "events (verb)" in target language and matched with same parts. Meanwhile, the translator also needs to consider contact intentions, writing style, readers comprehension ability in achieving the closest natural equivalence.

\section{Choice of Words}

In the process of translation, we need to understand the idioms first.

On November 15th, 2012, General Secretary Xi Jinping delivered his first public address at the first plenary session of the 18th CCPC, the speech was quite down-to-earth and a Chinese idiom like “打铁还需自身硬” has various translation versions.

The on-site interpretation, delivered by the interpreter Sun Ning, is "To be turned into iron, the metal itself must be strong"; the version provided by CNN in its article was "To forge iron one must be strong"; while the official English version of the idiom provided by state media Xinhua News Agency turned out to be "To address these problems, we must first of all conduct ourselves honorably". 
There are other idioms heard by different people and translated differently. For example "To embroider flowers, one's hand must be clever (绣花要得手棉巧) ", it means if one wants to embroider a flower, she must be skillful to do it. Because the form is antithetical , so they tend to convey same idea. Hence the right understanding is "To forge iron one must be strong".

Likewise the examples of President Hu Jintao's remarks on the conference of $30^{\text {th }}$ anniversary of reform and opening-up, he put up forward a word “不折腾”. Various experts and numerous netizens answered diversely. "Don’t flip-flop " or "Don’t move sideways" or "Stop making trouble and wasting time" or "Avoid futile actions ". Translator Gao who once served President Deng Xiaoping suggested translating it as "Don't do much ado about nothing”. Because in English, "much ado about nothing"is established, which means works repeatedly but in vain. Obviously, this expression is vivid and more appropriate.

From above it can be concluded that accurate words are used to clinch the point. Just as Mark Twain once said: "The difference between the right word and the almost right word is the difference between lighting and a lighting bug." So we could know the words and use them well.

\title{
Choice of Sentence Structures
}

Adjustment sentence structure and combine several choppy sentences into fewer, smoother ones can make translation more easily and orderly, like used the way of parallel construction, Parataxis, combination of sentence pattern.

\author{
弗虑胡 获,弗为胡 成. \\ Those who don't think, acquire nothing; those who \\ don't act, achieve nothing. \\ 道虽迩, 不行 不至; 事 虽 小, 不为不成 \\ Even the shortest journey can't be finished without \\ taking the first step, even the most trivial task can't be \\ completed without taking actions. \\ 万物各得其和以生, 各得其养以成 \\ All things live in harmony and grow with nourishment. \\ 相 互 呼应, 相 得 益彰。 \\ Reinforce each other and that by working together \\ 一地之难, 一 时之急 \\ These are only isolated cases. \\ 唇齿相 依, 兴衰相 伴。 \\ As close as lips and teeth
}

\section{Choice of Expressions}

Due to the unique characteristics of Chinese idioms, particularly features of interpreting, an interpreter still needs some strategies to deliver the meaning with equal force and terseness in a second.

Repetition and word adding: Sometimes, it is unavoidable to satisfy some grammatical or rhetorical requirements, especially in idioms interpretation, to put emphasis, to achieve the strong rhythm and other special purposes. Meanwhile, during the process, interpreters need time to think under great pressure while no suspense of language reproduction is allowed. At this time, repetition and word adding are the best way to release pressure and gain more time to think. Words added may be the original word or synonyms.

Supplementation: The meaning of a word, a sentence or a discourse will be more or less lost if it is taken away from its context. If the speaker neglects this point, the interpreter should instead make up for it and speaks the meaning out. In cases of idioms which carry a lot of cultural or social connotation, 
supplementation is a must in interpretation to convey the speaker's intention correctly and completely. Sometimes, words are supplemented to clarify and to detail the literal interpretation according to the speaker's knowledge about the issue concerned.

Omission: In order to save time and keep pace with the speakers, the interpreter has to omit unnecessary or superfluous words or expressions that do not conform to the usage of the target language, provided that the original meaning is not distorted.

As in Chinese idiom expressions there's no lack of repetition, antithesis, symmetry and rhythmic wording and by contrast, English tends to be concise and tries to avoid repetition as much as possible, the interpreter is naturally expected to omit redundant or unnecessary repetition in C-E interpretation.

Parsing in interpretation means to segment long and logically complex sentences into fragment so that interpreters can deal with the meaning unit in time with more ease and less pressure. This strategy also serves for facilitation of understanding among audience. Parsing must be swift and reasonable for better coherence so as to reconnect those meaning unit naturally.

Meanwhile, Translator must understand the speaker's intention from knowledge and emotion, but also acknowledge receptor's concern to manage the implied culture factors well.

At the Fourth Session of the Twelfth National People's Congress press conference, president Li Keqiang talked about general election and said:

“不管花落谁家, 最后谁当总统, 我相信中美关系向前发展的大势不会改变.”

The translation is " I believe that no matter, in the end, who gets into the White House, the underlying trend of China-US ties will not change.” The words $\mid$ “花落谁家” was translated into "who gets into the White House", not "where have all the flowers gone", a more general translation. So we could see the effect is very different.

\section{Conclusion}

Idioms, being the embodiment of culture, should always be viewed from cultural perspective. As a result, the interpretation of idioms could not be secured if the interpreter lacks cultural familiarity. Diversified characteristics of Chinese idioms remind us to accumulate knowledge in different field and get familiar with local history. Understanding the relationship between image and associative implication, interpreters need to gasp the point of delivering the meaning and occasionally eliminate images and in long terms to digest continually on target language. By using translation strategies within current political context, choice of words and sentence patterns all need to be flexibly processed in metaphorical Chinese idioms. Comparing literal translation with liberal translation and analyzing the reason why the senior translator chooses certain words, sentence structures and expressions can help translators to practice the rules into other translation. Meanwhile, separating parts clearly will help translators to find the corresponding in target language. Putting cultural background into translation can clinch the point of political speech or remarks and get them presented clearly and precisely.

\section{References}

[1] Alexander Fraser T, Essay on The Principles of Translation [M]. Shanghai: Foreign Language Teaching and Research Press, 2007.

[2] Christina Schaffner, Translation and Norms [M]. Shanghai: Foreign Language Teaching and Research Press, 1999.

[3] Zong Zhaorong, Metaphorical Thinking and Translation of Chinese Idioms [MA]. 2006.

[4] Li Yida, 2012, Strategies for Chinese Idioms Interpretation [MA].

[5] Susan, B, Translation Studies [M], Shanghai: Foreign Language Teaching and Research Press, 2007. 
[6] Xu Dongxia, The translation of idioms in a cultural discrepancies perspective [MA], 2008.

[7] Cao Pei, Strategies for English translation of Chinese idioms [MA]. 2013.

[8] Wang Shaodi, Research on Lin Yutang's translation [M], Shanghai Foreign Language Education press, 2011. 